\title{
Mercado de trabajo, temporalidad ilícita, engaño \\ y deshonestidad
}

\author{
Labor market, illegal temporality, deception \\ and dishonesty
}

Ignasi Beltran de Heredia Ruiz

Profesor Agregado y TU Acreditado.

Universitat Oberta de Catalunya (UOC)

ORCID ID: 0000-0002-4218-7569

doi: https://doi.org/10.20318/labos.2021.6221

\section{Temporalidad ilícita y el engańo como uno de los factores explicativos de la contumaz resis- tencia al cumplimiento de la ley}

Una de las particularidades del mercado de trabajo español es, como es bien conocido, su elevada y persistente tasa de temporalidad.

Al cierre de este trabajo, según los últimos datos de la encuesta de población activa del INE (2021/1T), aunque ha mejorado sensiblemente respecto del semestre anterior, este índice sigue cerca del 24\%. Y aunque algunos indicadores sugieren una cierta mejora reciente (como la duración media de los contratos), en abril de 2021, el 87,91\% de los contratos formalizados siguían siendo temporales (indicador que, en los últimos años, nunca ha podido bajar del $85 \%$ en la serie mensual), sin olvidar su tendencia a comportarse de forma absolutamente "bulímica" en determinados períodos del calendario (semanal/anual).

Es evidente que un porcentaje (muy) elevado de estos contratos no responden a las causas de temporalidad legalmente descritas.

En definitiva, nos enfrentamos a un fenómeno patológico que se ha cronificado (y, en paralelo, amplios sectores de la economía se han hecho muy dependientes de la precariedad que este fenómeno supura).

Los factores que han podido influir en la consolidación de esta "tendencia" empresarial pueden ser múltiples y de naturaleza muy heterogénea. Es obvio que el carácter cíclico de importantes sectores de la economía, las "particularidades" del sector público, así como el fomento del empleo a través de la contratación temporal no sometida a una causalidad desde finales de los años 70 hasta principios de los 90 del siglo pasado han podido tener una influencia determinante. Y tampoco puede omitirse que algunos criterios jurisprudenciales también han jugado un papel estimulador de la temporalidad. En paralelo, es obvio que el estatuto protector asociado al contrato indefinido y la supresión en 2012 de los salarios de tramitación (salvo readmisión) también son factores que podrían estar influyendo de forma decisiva (del mismo modo que las "cargas" asociadas al trabajo

*ibeltran_de_heredia@uoc.edu 
subordinado, también explicarían la huida hacia fórmulas de trabajo autónomo o económicamente dependiente fraudulentas).

Pasadas todas estas décadas, quizás, no sea descabellado hablar de la existencia de una "cultura” empresarial de la temporalidad. Con todo lo que esto implica ${ }^{1}$.

Si esto fuera así, es claro que el problema estaría anclado a unos factores y/o parámetros cuya complejidad y comprensión son especialmente profundas (o mucho mayores de lo que, quizás, se ha dado a entender y/o los juristas hemos sido capaces de apreciar). Por consiguiente, si esta hipótesis se confirmara, podría colegirse que, parte del fracaso en la lucha contra la temporalidad se deba a un defecto, en esencia, "primario" o de "punto de partida". Es decir, seguimos sin tener un diagnóstico claro y, por lo tanto, al desconocer la dimensión "real" del problema llevamos un tiempo, si me permiten la expresión, dando palos de ciego.

Esto podría dar una explicación a un hecho difícilmente discutible: la escasa efectividad de las medidas legales dirigidas a combatir la excesiva temporalidad. La "potencia de fuego" que estamos empleado ha sido (está) siendo manifiestamente "corta". En efecto, el transcurso del tiempo y la escasa variabilidad en la tasa de temporalidad (salvo en los períodos recesivos - por motivos obvios) es la muestra más evidente de que la batería de instrumentos normativos empleados hasta la fecha sólo ha sido capaz de "rascar" en la superficie del problema.

La complejidad del fenómeno es especialmente visible cuando se constata que la contratación temporal ilícita es una opción significativamente penalizada (especialmente, desde un punto de vista económico). De hecho, el coste de su extinción es superior al de un contrato indefinido ${ }^{2}$. Extremo que ilustra que las aproximaciones estrictamente apegadas a una mera valoración costebeneficio o, si lo prefieren, a la "racionalidad" que orbita alrededor de la falacia del homo economicus (por -entre otros motivos- su carácter absolutamente tautológico ${ }^{3}$ ) también se quedan "cortas".

Lejos de los planteamientos maximalista propios de lo que se conoce como "imperialismo económico", los avances en diversas ciencias sociales, como la psicología de la conducta y/o la psicología social (pese a sus limitaciones) han desvelado la riqueza y heterogeneidad de factores que podrían influir en el comportamiento humano. En el fondo, a partir de la racionalidad estratégica del individuo (y no meramente paramétrica), la arquitectura de las decisiones que toda norma lleva implícita es susceptible de sufrir un defecto crítico si no tiene mínimamente en cuenta las palancas que, a nivel introspectivo (e, incluso, por debajo del nivel consciente), precipitan nuestro comportamiento ${ }^{4}$. Y, por ende, que podrían explicar la resistencia contumaz al cumplimiento del mandato legal en favor de la contratación indefinida.

En este sentido, si bien es cierto que el marco normativo y los vaivenes hermenéuticos puedan dificultar que el destinatario de la norma sepa a ciencia cierta si, efectivamente, su comportamiento se ajusta o no al mandato de la ley, es posible que no sean pocos los empresarios que sean plenamente conscientes de que su conducta claramente está fuera del marco legal e, incluso, hayan llegado a normalizar este comportamiento deshonesto (o, si lo prefieren, contrario a la "virtud cívica").

\footnotetext{
${ }^{1}$ Aunque las leyes tienen una "función expresiva", en tanto que hablan en nombre de la opinión de la mayoría (y, en parte, es una función de su autoridad moral), al crearse una "cultura de la temporalidad" en una "subcomunidad" de la sociedad, sus señales "pueden no tener ninguna importancia o incluso ser contraproducentes. Puede que una ley diga '¡no!', pero algunas personas querrán decir “jsí!”. Cass R. Sunstein, La conformidad, Ciudad de México, Instituto Nacional Electoral, 2020, p. 25.

${ }^{2}$ Ignasi Beltran De Heredia Ruiz, Sesgos y pautas del comportamiento empresarial y temporalidad ilícita, Iuslabor, 3, 2019, 125 y 126.

${ }^{3}$ Entre otros, extensamente, Jon Elster, La explicación del comportamiento social, Barcelona, Gedisa, 2010, p. 186 y 215 y ss. O, incluso (Robert Trivers, La insensatez de los necios, Buenos Aires, Katz, 2013, p. 326 a 329), se rechaza que la economía pueda ser calificada como una "ciencia".

${ }^{4}$ Las recientes conversiones masivas de contratos temporales a indefinidos a partir de las campañas del Ministerio de Trabajo consistentes en el envío de una simple carta a los empresarios son especialmente ilustrativas de la potencialidad de esta dimensión "introspectiva" en el cumplimiento de la norma.
} 
En este contexto, una de las preguntas que, quizás, debamos dar respuesta es por qué somos deshonestos ante la norma y, especialmente, cuando lo hacemos, qué hacemos para, mediante el autoengaño, convencernos para "normalizar" este comportamiento y seguir operando al margen de la ley. Es claro, pues, que si no sabemos por qué la gente actúa de este modo en el uso de la temporalidad, difícilmente podrá articularse una respuesta efectiva que trate de combatir este gran problema que mina nuestro mercado de trabajo.

Vaya por delante que esta aproximación, necesariamente breve, no aspira a explicar (unicausalmente) por qué se ha llegado a conformar una "cultura de temporalidad" anteriormente descrita. El problema (como se ha apuntado) es ciertamente más alambicado y en el anidan múltiples capas de complejidad profundamente imbrincadas. El propósito, mucho más modesto, es proyectar una de las posibles dimensiones que, junto con otras muy "poderosas" ${ }^{5}$, podrían acabar incidiendo en la toma de decisión empresarial al escoger la modalidad de contratación. En definitiva, el propósito es tratar de dar algo de luz sobre este fenómeno.

\section{Sobre el engańo y la deshonestidad}

El alineamiento de una persona al mandato de la Ley podría estar estrechamente vinculado a la probabilidad (mayor o menor) de ser descubierto. Conforme a este modelo de conducta (basado en un "simple" análisis de coste-beneficio), bastaría con incrementar las sanciones y/o la probabilidad de sorprender a los infractores para reducir las conductas alejadas del ideal normativo. Son muchas las normas que responden a este planteamiento. Y, lamentablemente, su efectividad está lejos de alcanzar los objetivos propuestos.

En efecto, lejos de los planteamientos basados en la teoría racional del delito (BECKER), conviene tener en cuenta que, por un lado, nuestro exceso de confianza nos lleva a hacer estimaciones sobre el acaecimiento de eventos del futuro muy alejados de la realidad. En efecto ${ }^{6}$, en la medida que somos incapaces de pensar estadísticamente, padecemos una notable y desconcertante limitación cognitiva que se traduce, primero, en una sobreestimación de lo que creemos saber; y, segundo, en una aparente incapacidad para reconocer las dimensiones de nuestra ignorancia y la incertidumbre del mundo en que vivimos.

Y, por otro lado, diversos experimentos han demostrado que "la probabilidad de ser descubierto no tiene una gran influencia en la magnitud del engaño" 7 . Es obvio que la probabilidad de ser "atrapado" influye (nadie comete un delito delante de una comisaría de policía). Ahora bien, estos estudios sugieren que "el hecho de ser sorprendido no tiene tanta importancia como cabría esperar". De hecho, en la medida que estas investigaciones apuntan a que, pudiendo engañar mucho, tendemos a hacerlo sólo un poco, permite llegar a la conclusión de que "engañamos hasta el nivel que nos permite conservar nuestra imagen de individuos razonablemente honestos".

En efecto, si nos sentimos cómodos con un cierto nivel de engaño, esto es, toleramos con cierta intensidad nuestra deshonestidad, se desvela una dimensión de suma importancia, pues, hasta cierto punto, queremos sacar provecho de la misma. En el fondo, a pesar de la carga cognitiva que toda mentira lleva aparejada ${ }^{8}$, podría decirse que cada uno de nosotros tiene su propio "nivel de deshonestidad".

\footnotetext{
${ }^{5}$ Sobre los diversos factores (sesgos e heurísticas) que podrían incidir a nivel introspectivo (o, incluso, por debajo del nivel consciente), véase extensamente, Ignasi Beltran De Heredia Ruiz, Sesgos y pautas del comportamiento empresarial y temporalidad ilícita, op. cit., 126 a 147.

${ }^{6}$ Daniel Kahneman, Pensar rápido, pensar despacio, Barcelona, Debolsillo, 2012, p. 27.

${ }^{7}$ Dan Ariely, Por qué mentimos, Barcelona, Ariel, 2012, p. 30 y 31.

${ }^{8}$ Robert Trivers, La insensatez de los necios, op. cit., p. 26.
} 
De modo que, lejos de los planteamientos propios de coste-beneficio, la intensidad de nuestra honestidad, ¡no tiene una correlación directa con la probabilidad de ser descubiertos!?.

Lo que, a su vez, desvela la profunda complejidad de nuestro comportamiento (con evidentes consecuencias adversas). En este sentido, "la capacidad humana de engańar es enorme. Tenemos la enervación de músculos faciales más compleja y utilizamos un gran número de neuronas motoras para controlarlos -ninguna otra especie puede poner cara de póker-. Y tenemos el lenguaje, ese medio extraordinario para manipular la distancia existente entre el mensaje y su significado. Los humanos también somos excelentes mintiendo porque nuestras capacidades cognitivas nos permiten hacer algo que va más allá de lo realizado por cualquier pérfido gelada: podemos 'afinar' la verdad" 10 . Y lo más "interesante" es que "a nosotros nos juzgamos por nuestros motivos internos y a todos los demás por sus acciones externas. De modo que, al considerar nuestras propias fechorías, tenemos más acceso a información atenuante, circunstancial" ${ }^{11}$.

En definitiva, nos regimos por un extraordinario y flexible "factor de tolerancia" que nos permite engañar sólo un poco, de modo que podemos seguir sintiéndonos bien con nosotros mismos ${ }^{12}$. Es decir, cada uno de nosotros tiene su propio límite (algunos más estricto que otros).

Y, a través de esta racionalización de nuestras conductas ejecutadas "fuera de los límites", conseguimos que nuestra deshonestidad nos sea invisible (no la vemos en nosotros mismos). De modo que, si somos capaces de autoindultarnos, no tenemos ningún inconveniente en seguir actuando de forma "desviada".

Y es en este espacio en el que el "autoengaño" adquiere un papel destacado. Partiendo de la base de que el engaño es algo "omnipresente" (pues, es practicado en todos los niveles de la vida - virus, bacterias, plantas, insectos y muchos animales), hay autores que entienden que el autoengaño es "un producto evolutivo que sirve para engatusar mejor a los otros", pero también permite "reducir la carga cognitiva" o, en otras ocasiones, "proporciona una defensa fácil contra las acusaciones de engaño"13.

El autoengaño ${ }^{14}$ describe un proceso mental particularmente complejo, pues, implica el almacenamiento "en la mente de información verdadera y falsa, con la salvedad de que la información verdadera se guarda en la parte inconsciente y la falsa en la parte consciente. A veces, ese proceso entraña actividades de la mente consciente -como la supresión activa de recuerdos-, pero habitualmente los procesos mismos son inconscientes, aunque distorsionen aquello de lo que somos conscientes". Así pues, la clave para definir el autoengaño "es tener en cuenta que la información verdadera queda por lo general excluida de la conciencia y que - de conservarse en ella - se almacena en diversos grados de inconsciencia. Si la mente actúa con suficiente celeridad, no es necesario que se almacene ninguna versión de la verdad. Hay un hecho contraintuitivo que es necesario explicar: que la información falsa se guarda en la mente consciente" ${ }^{15}$. De modo que este proceso contraintuitivo "existe pura y exclusivamente para manipular a otras personas. Nos ocultamos la realidad

\footnotetext{
${ }^{9}$ Dan Ariely, Por qué mentimos, op. cit., p. 28.

${ }^{10}$ Robert M. SAPOLSKY, Compórtate, Barcelona, Capitan Swing, 2018, p. 724.

${ }^{11}$ Robert M. SAPOLSKY, Compórtate, op. cit., p. 699. Y añade: "la tendencia a juzgarnos a nosotros mismos con menos dureza que a los demás se resiste a la racionalización de la disuasión” (y para una descripción neurobiológica de la mentira, véase p. 725 a 732 ).

${ }^{12}$ Dan Ariely, Por qué mentimos, op. cit., p. 34, 35 y 226. Es lo que este autor califica como la "teoría del factor de tolerancia”.

${ }^{13}$ Robert Trivers, La insensatez de los necios, op. cit., p. 23 y 20. Añadiendo (p. 20) que "en el primer caso, quien se autoengańa no brinda los indicios que acompañan el engaño consciente y así elude que lo detecten. En el segundo caso, el proceso concreto de engañar resulta menos costoso cognitivamente porque parte de la verdad queda en el inconsciente. En otras palabras, el cerebro puede funcionar más eficazmente si ignora la contradicción. En el tercer caso, si el engańo se advierte, es más fácil defenderlo - es decir, racionalizarlo - ante los demás como algo que se propagó de manera inconsciente".

${ }^{14}$ Siguiendo la exposición de Robert Trivers, La insensatez de los necios, op. cit., p. 25.

${ }^{15}$ No obstante, sobre esta cuestión la doctrina no es pacífica. Jon ElsTer (La explicación del comportamiento social, op. cit., p. 161) afirma que (cierto) "autoengaño no implica el mantenimiento simultáneo de dos creencias contradictorias, una sostenida de forma consciente y otra, de forma inconsciente", pues, en determinados casos, cabe un reemplazo de una creencia por otra, de modo que se produce una desaparición para siempre, en vez de quedar relegada al inconsciente.
} 
para ocultarla mejor a otros. Puede suceder que guardemos una copia de la información verdadera, pero lo que sin duda hacemos es impedir que otros accedan a ella”.

Como se expondrá a continuación, hay ciertos factores que contribuyen a amplificar este razonamiento introspectivo (ciertamente, tan "maquiavélico" como común ${ }^{16}$ ).

\subsection{Distancia entre la acción deshonesta y sus consecuencias}

Diversas experimentaciones ${ }^{17}$ sugieren que, por ejemplo, estamos más dispuestos a robar algo que no tenga atribuido explícitamente un valor monetario (por ejemplo, el bocadillo del compañero de la nevera, un bolígrafo o el papel de la impresora) que dinero en metálico. $\mathrm{O}$, dicho de otro modo, "las personas tienden a ser más deshonestas en presencia de objetos no monetarios - como lápices o fichas - que ante dinero de verdad". Y, además, es preocupante observar ${ }^{18}$ que, cuando se nos da la oportunidad, hacemos trampas (aunque sólo un poco).

Y la clave para tratar de explicar este comportamiento es que identifiquemos la existencia de una "distancia" entre la acción deshonesta y sus consecuencias ${ }^{19}$. En este sentido, el tiempo juega un papel destacado (aunque no sólo), pues, incide poderosamente en la formación de relatos personales falsos, pues, sobreevaluamos nuestras conductas pasadas y, además, tendemos a recordar nuestras acciones morales negativas como su hubieran sucedido mucho tiempo antes que las acciones positivas ${ }^{20}$.

Si nuestras acciones están lejos de la ejecución del hecho fraudulento también resulta más fácil ser deshonesto. Por ejemplo, si la formalización del contrato a sabiendas ilícito no la hace directamente el empresario (sino un tercero en su nombre), es fácil que se cree un espacio de inmunidad (o una distancia psicológica lo suficientemente separada como para verse desvinculado de sus efectos ilícitos). Y también si las reglas no están claras también puede propiciar el mismo efecto (pues, en definitiva, puede pensarse que se está optando por una más de las "múltiples" interpretaciones al alcance).

En cualquier caso, esta "distancia" (entendida en sentido amplio) tiene un efecto determinante, pues, libera a la gente de sus ataduras morales, empeorando su brújula moral.

Lo peor es que los ámbitos en los que este comportamiento está presente son vastísimos. Así, por ejemplo, esto explicaría cierta condescendencia (o nulo reproche) con la percepción de ciertos obsequios no monetarios (lamentablemente famosos en ciertos ámbitos políticos) a cambio de "favores" o "preferencias"; u otras muchas prácticas dudosas o tramposas sin que medie directamente dinero en efectivo.

Y es obvio que el ámbito laboral no está exento en absoluto. En efecto, es factible pensar que esta "distancia", también podría explicar ciertas prácticas empresariales con sus trabajadores o con terceros (Seguridad Social, Hacienda y/o clientes) ${ }^{21}$.

En definitiva, el incremento de la distancia psicológica entre una acción deshonesta y sus consecuencias hace incrementar el factor de tolerancia y esto provoca que los seres humanos tiendan a

\footnotetext{
${ }^{16}$ Aunque escasean pruebas al respecto, parece ser que (Robert Trivers, La insensatez de los necios, op. cit., p. 107) "en el caso de los seres humanos adultos, cabe esperar que los individuos más inteligentes engañen más, y no menos, y que lo hagan con mayor habilidad (...). En teoría, además, se espera que los individuos más brillantes se autoengañen más que los menos dotados”.

${ }^{17}$ Dan Ariely, Por qué mentimos, op. cit., p. 38 y ss.

${ }^{18}$ Dan Ariely, Las trampas del deseo, Booket, 2013, p. 240.

${ }^{19}$ Dan Ariely, Por qué mentimos, op. cit., p. 37 y 39.

${ }^{20}$ Robert Trivers, La insensatez de los necios, op. cit., p. 41. En términos similares, Dan Ariely (Por qué mentimos, op. cit., p. 144) apunta que

${ }^{21} \mathrm{Y}$ también el propio comportamiento de los trabajadores. Por ejemplo, quizás, también podría explicar el caso resuelto por la STS de 21 de septiembre de 2017 ( $\mathrm{R}^{\circ}$. 2397/2015, Sala de lo Social) en relación al despido de una cajera-reponedora que se apropió de determinados productos de alimentación en otro supermercado de la misma empresa, distinto al que constituía su centro de trabajo en el que prestaba servicios
} 
engañar más ${ }^{22}$. Y diversos estudios sugieren que, si se toma consciencia de la posibilidad de llevar a cabo una conducta deshonesta (por ejemplo, añadiendo patrones éticos antes de la toma de determinadas decisiones), reflexionamos sobre la misma y, por este motivo, se incrementa la honestidad ${ }^{23}$.

\subsection{Sesgo de confirmación}

El engańo o la deshonestidad generan una disonancia cognitiva. Esto es, una contradicción psicológica que puede ser de intensidad desigual y que, de hecho, tratamos de reducir a través de una racionalización de esta conducta ${ }^{24}$. Y, como seres humanos, disponemos una gran habilidad para hacerlo: tenemos una sofisticada capacidad para (con razones aparentemente lógicas) justificar con extraordinaria frecuencia nuestros comportamientos deshonestos (y, especialmente -como se ha apuntado-, cuando no tienen que ver directamente con el dinero). Esto nos resulta ciertamente "útil", pues, permite distanciarnos del conocimiento de que estamos incumpliendo las normas ${ }^{25}$. De modo que "somos expertos a la hora de racionalizar nuestra pequeña deshonestidad" 26 . Y, ciertamente, no hay elementos para pensar que la formalización de un contrato temporal a sabiendas de que debería ser indefinido no participe de este modo de razonar.

Y, en este ámbito, lo que se conoce como el "sesgo de confirmación" tiene una capacidad poderosísima para "blanquear" nuestro comportamiento: "la persistencia en una creencia puede derivar de la negativa a abandonar una buena historia inventada para explicar algo que el sujeto cree que es verdad" 27 . Este "portavoz interno" 28 es especialmente hábil a la hora de justificar automáticamente todo, construyendo una "negación plausible" (y si algo nos irrita "es mucho más fácil justificar nuestra conducta inmoral" ${ }^{29}$ ). Con este propósito reconstruimos nuestros móviles y relatos internos con el propósito de justificar conductas censurables o cuestionables ${ }^{30}$. Y esta negación genera una especie de espiral "tóxica", porque exige ratificaciones posteriores, pues, "una vez se ha incurrido en la primera negación, la tendencia es corroborarla: [se niega] primero, luego [se niega]

\footnotetext{
${ }^{22}$ Dan Ariely, Por qué mentimos, op. cit., p. 37 y 60.

${ }^{23}$ Dan Ariely, Por qué mentimos, op. cit., p. 43 y ss.

${ }^{24}$ Robert Trivers, La insensatez de los necios, op. cit., p. 168. Siguiendo a Anastasio Ovejero Bernal (Psicología Social, Madrid, Biblioteca Nueva, 2015, p. 215), la disonancia es motivacional: "la propia existencia de la disonancia empuja al individuo a intentar eliminar, o al menos a reducir, tal estado de disonancia. Y cuanto más fuerte sea la disonancia más fuertes serán también las presiones para intentar eliminarla o reducirla. Por consiguiente, la teoría de la disonancia cognitiva es, ciertamente, una teoría cognitiva, pero es también, y en alto grado, una teoría motivacional'.

${ }^{25}$ Dan Ariely, Por qué mentimos, op. cit., p. 165.

${ }^{26}$ Dan Ariely, Las trampas del deseo, op. cit., p. 237.

${ }^{27}$ Stuart SutherLand, Irracionalidad: el enemigo interior, Alianza Editorial, 2015, p. 205. Y, siguiendo con este autor (p. 74), nuestro entorno tampoco ayuda a transigir. En efecto, en la medida que tendemos a juntarnos con nuestros iguales, es poco frecuente que estemos expuestos a argumentos que sean contrarios a nuestras más profundas convicciones, y mucho menos a pruebas contrarias a ellas. Nuestras creencias se ajustan a las de nuestros compańeros, de modo que hay pocas posibilidades de eliminar los errores persistentes.

${ }^{28}$ Así lo denomina Jonathan HAIDT, La mente de los justos, Deusto, 2018, p. 124. Las investigaciones sobre la neurofisiología del engaño y el autoengaño empiezan a mostrar que (Robert Trivers, La insensatez de los necios, op. cit., p. 69 y 71) "el papel que desempeña la mente consciente para orientar nuestra conducta es mucho menos importante de lo que se suponía. Contrariamente a lo que imaginábamos, la mente consciente siempre está a la zaga del inconsciente en la acción y en la percepción: se parece más a un observador que un actor que toma la iniciativa. (...). Se estima que unos diez segundos antes de que exista conciencia de la intención, se disparan señales neuronales que luego darán origen a la conciencia y más tarde al comportamiento mismo". Esto encajaría con la idea que sugiere HaIDT, pues, de algún modo, actuamos impulsivamente y, post-hoc, el "portavoz" se encargaría de justificar nuestra reacción (especialmente si ya no puede ser cambiada).

${ }^{29}$ Dan Ariely, Por qué mentimos, op. cit., p. 160. En estos casos, la "deshonestidad se torna represalia, una acción compensatoria contra cualquier cosa que de entrada nos exaspere".

${ }^{30}$ Robert Trivers, La insensatez de los necios, op. cit., p. 162.
} 
que se ha negado y así sucesivamente" 31 . Derivando, en definitiva, en una especie de "escalada del compromiso" y que lleva a mantener una decisión inicial aunque "los hechos la ponen clara y seriamente en tela de juicio" ${ }^{2}$.

Esta inmunización frente a nosotros mismos aumenta nuestra capacidad para ser deshonestos (y nos da argumentos para continuar siéndolo en el futuro) y, al mismo tiempo, no impide que sigamos considerándonos comprometidas con los deberes cívicos. En efecto, como se ha apuntado anteriormente, en la medida que engañamos lo justo para sentirnos bien con nosotros mismos, nos movemos por debajo del umbral de lo intolerable (garantizándonos una "inmunidad moral perpetua”). El límite se encuentra en el instante que ya no somos capaces de encontrar una justificación que conserve nuestra creencia en nuestra propia honestidad ${ }^{33}$.

De algún modo ${ }^{34}$, estos engaños se encuentran en los límites inferiores de la deshonestidad humana. Es decir, se refieren al nivel de engaño que practican las personas que aspiran a ser éticas y que desean verse a sí mismas como éticas. De modo que, a pesar de tener una alta consideración de nosotros mismos en términos de bondad y rectitud moral, no somos inmunes a nuestra ceguera mental y podemos acabar realizando acciones que prescinden de nuestras pautas morales a fin de obtener diversas compensaciones (sin dudar de nuestra propia virtud).

Y esta forma de pensar resulta particularmente inquietante (¿no creen?).

Y lo expuesto, quizás, explicaría la (asombrosa) perplejidad que muestran algunos cuando se descubren las corruptelas, trampas o engaños que han estado cometiendo de forma reiterada en el tiempo.

\subsection{El engaño es infeccioso (una derivada del conformismo)}

Es evidente que la conducta humana no puede explicarse únicamente en términos internos, sino que puede estar fuertemente influenciada por el entorno. Así que, para entender la complejidad de nuestro comportamiento, es esencial tener en cuenta el medio físico y social en el que nos movemos ${ }^{35}$. De ahí que el papel de la cultura colectiva sea esencial para poder aspirar a mejorar nuestra conducta.

El conformismo es un fenómeno ampliamente analizado en la psicología social. En concreto, "puede definirse como un cambio en la conducta u opiniones de una persona como resultado de una presión real o imaginada de personas o grupos de personas" ${ }^{\prime 6}$. De hecho, las personas pueden llegar a falsear "su propio conocimiento, o como mínimo pasarán por alto sus propias dudas, cuando estén frente a las opiniones manifiestas de la masa" ${ }^{37}$. En otras ocasiones, puede estar causada por una falta de información y/o bien por nuestra voluntad por agradar o mantener la buena opinión que tengan de nosotros ${ }^{38}$. Y también es posible que, como si de un "pegamento social" se tratara ${ }^{39}$, se produzcan cascadas de conformidad, de modo que ciertas creencias (incluso falsas) se propaguen ampliamente ${ }^{40}$; incluso entre "generaciones" ${ }^{41}$. Por ejemplo, la posibilidad de celebrar un "contrato temporal de prueba” es, quizás, una de las creencias falsas más extendidas.

\footnotetext{
${ }^{31}$ Robert Trivers, La insensatez de los necios, op. cit., p. 166.

${ }^{32}$ Anastasio Ovejero Bernal, Psicología Social, op. cit., p. 224.

${ }^{33}$ Jonathan Haid, La mente de los justos, op. cit., p. 130.

${ }^{34}$ Dan Ariely, Las trampas del deseo, op. cit., p. 244 y 245.

${ }^{35}$ Gerd Gigerenzer, Decisiones instintivas, Barcelona, Ariel, 2018, p. 88 y 89.

${ }^{36}$ Siguiendo a Elliot Aronson, El animal social, Alianza Editorial, 2018, p. 36.

${ }^{37}$ Cass R. Sunstein, Rumurología, Debate, 2a Ed, 2010, p. 54.

${ }^{38}$ Cass R. Sunstein, La conformidad, op. cit., p. 20 y 22.

${ }^{39}$ Cass R. Sunstein, La conformidad, op. cit., p. 14.

${ }^{40}$ Cass R. Sunstein, Rumurología, op. cit., p. 54.

${ }^{41}$ Cass R. Sunstein, La conformidad, op. cit., p. 28
} 
Desde este punto de vista, no debe sorprendernos que el engaño pueda aumentar cuando observamos una mala conducta de quienes nos rodean ${ }^{42}$. Y estas "fuerzas sociales" circundantes parece que funcionan de dos formas distintas: si quien engaña forma parte de nuestro grupo social, nos identificamos con él y, en consecuencia, puede parecernos que engañar es más aceptable desde el punto de vista social. Ahora bien, si no pertenece a nuestro grupo, es probable que nos cueste más justificar que llevemos a cabo una conducta deshonesta y, por ello, tengamos tendencia a distanciarnos de esa persona.

En definitiva, el entorno social es determinante a la hora de definir nuestros límites de lo que es aceptable, incluido el engaño. En efecto, "si vemos a los otros miembros de nuestros grupos sociales comportarse de manera no aceptable, es probable que también reconsideremos la brújula moral interna y adoptemos su conducta como modelo propio. Y si el miembro de nuestro grupo afín resulta ser una figura con autoridad -padre, jefe, maestro o alguien a quien respetamos-, aún hay más posibilidades de que nos veamos arrastrados a ello" ${ }^{33}$.

De hecho, basta con que tengamos una falsa percepción sobre el comportamiento de los demás para inducirnos a incumplir las normas. El hecho de que "nuestras acciones concuerden con las normas sociales de quienes nos rodean suele servirnos de consuelo" ${ }^{44}$. E, incluso, pueden llegar a que excusemos las malas conductas. De ahí que "la conducta observada públicamente tiene un gran impacto en quienes la observan", de modo que la "mala conducta de esa misma gente puede tener grandes consecuencias descendentes en la sociedad en general" 45 .

Esto pone de manifiesto el efecto devastador que las reacciones tibias frente a la deshonestidad de personajes públicos. Y, en el lado opuesto, es esencial dar a conocer los actos de honestidad (publicitándolos), pues, contribuyen de forma poderosa a nuestro sentido de la moralidad social. En efecto, cuanto más probable resulte que una expresión legal sea efectiva, las transgresiones de la ley serán muy visibles, y la visibilidad importa porque la gente no quiere despertar la ira de los demás ${ }^{46}$.

En este sentido, pueden implementarse estrategias para fomentar el cumplimiento de la legislación acudiendo al sesgo de conformidad ${ }^{47}$. Las diversas campañas de envío de cartas por parte del Ministerio a colectivos específicos dirigidas a la conversión de contratos temporales en indefinidos, probablemente, quedaría integrada en esta categoría de medidas ${ }^{48}$. Y su éxito (medido en el número de transformaciones y de recursos públicos invertidos para ello) es un ejemplo paradigmático del potencial de este tipo de estrategias (y de la necesidad de explorar nuevas intervenciones a partir del conocimiento introspectivo de los destinatarios de las normas).

\section{Una breve valoración final}

Hay numerosas situaciones en las que no somos capaces de ver nuestra deshonestidad o, viéndolas, somos lo suficientemente condescendientes como para no reprochárnosla, describiendo comportamientos jurídicamente ilícitos y, al ser racionalizados, persistentes en el tiempo. No debe sorpren-

\footnotetext{
42 Dan Ariely, Por qué mentimos, op. cit., p. 183.

${ }^{43}$ Dan Ariely, Por qué mentimos, op. cit., p. 184.

${ }^{44}$ Dan Ariely, Por qué mentimos, op. cit., p. 174.

45 Dan Ariely, Por qué mentimos, op. cit., p. 191 y 192.

${ }^{46}$ Cass R. Sunstein, La conformidad, op. cit., p. 101.

${ }^{47}$ Como exponen Richard H. Thaler y Cass R. Sunstein (Un pequeño empujón, Barcelona, Taurus, 2009, p. 85 y 86), “algunos contribuyentes tienden a violar la ley por la percepción equivocada - seguramente basada en los casos que airean los medios de comunicación - de que el porcentaje de ciudadanos que cumplen la ley es bastante bajo". Pues bien, como exponen dichos autores, en un experimento llevado a cabo en Estados Unidos (Minnesota) se constató que a los ciudadanos "cuando se les informó [mediante el envío de una carta] de que el cumplimiento de la Ley era en realidad alto, la posibilidad de que defraudaran se redujo".

${ }^{48}$ Sin perjuicio de que, al recibir la carta también podría suceder que el riesgo a ser sancionado se percibiera de forma más vívida (a partir de lo que se conoce como sesgo de disponibilidad) y ello contribuyera también a la buscada conversión.
} 
dernos, entonces, que si se dan índices altos de violación de las reglas en una comunidad se reduzca el capital social y ello alimente el comportamiento individual antisocial ${ }^{49}$.

Si no somos capaces de averiguar cómo podemos cambiar el modo de racionalizar o justificar nuestras acciones deshonestas, difícilmente el legislador será capaz de corregir las altas tasas de temporalidad (así como otros muchos conflictos y/o problemas jurídico-laborales o no).

Existe una relación directa entre una capacidad de racionalización amplia y el incremento del factor de tolerancia frente a la deshonestidad. Lo que se traduce en una delimitación de una "zona de confort" propicia para el engaño y el comportamiento desviado. Y, a la inversa, si se restringe la capacidad de racionalización de nuestras acciones, el factor de tolerancia también se ve menguado y, por consiguiente, "las trampas nos incomodan más" 50.

En la medida que tenemos una gran capacidad para distanciarnos del conocimiento que nos advierte del incumplimiento de las normas, es imprescindible tratar de activar mecanismos que nos hagan reflexionar sobre las dimensiones cívicas implícitas en nuestras decisiones. La clarificación de las normas juega en el engańo un papel destacado, pues, contribuye a limitar la posibilidad de que se racionalice una "interpretación" ilícita como una más de las opciones a nuestro alcance. Aprovechando la fuerza de las cascadas de conformidad, las campańas públicas dirigidas a recuperar la "salud ética" 51 pueden ser un buen complemento a otras actuaciones ya existentes. La exitosa estrategia de las cartas del Ministerio anteriormente descrita (aunque, hoy por hoy, se desconozca si su eficacia será replicable en el tiempo indefinidamente), al menos, ha mostrado que existen instrumentos poderosos y escalables que pueden incidir en las tomas de decisión individual en masa. La inclusión de compromisos éticos con carácter previo a la firma de determinados documentos (es decir, "patrones morales" o "recordatorios en el momento de la tentación" ${ }^{\prime 2}$ ) también podría contribuir a incrementar nuestra incomodidad al cometer un acto deshonesto ${ }^{53}$. La virtud de esta estrategia es que todas estas medidas son compatibles con las ya existentes (e, incluso, algunas de ellas, han mostrado una eficacia muy superior).

Creo que, a pesar de esta dolorosa flaqueza humana, quizás, la buena noticia es que podemos hacerla visible y, al identificarla, tratar de controlarla y, en el mejor de los casos, corregirla.

\section{Bibliografía citada}

DAN ARIELY, Por qué mentimos, Barcelona, Ariel, 2012.

DAN ARIELY, Las trampas del deseo, Barcelona, Booket, 2013.

ELLIOT ARONSON, El animal social, Madrid, Alianza Editorial, 2018.

IGNASI BELTRAN DE HEREDIA RUIZ, Ignasi, Sesgos y pautas del comportamiento empresarial y temporalidad ilícita, Iuslabor, 3, 2019, 114-151.

JON ELSTER, La explicación del comportamiento social, Barcelona, Gedisa, 2010.

GERD GIGERENZER, Decisiones instintivas, Barcelona, Ariel, 2018.

JONATHAN HAIDT, La mente de los justos, Barcelona, Deusto, 2018.

DANIEL KAHNEMAN, Pensar rápido, pensar despacio, Barcelona, Debolsillo, 2012.

ANASTASIO OVEJERO BERNAL, Psicología Social, Madrid, Biblioteca Nueva, 2015.

\footnotetext{
${ }^{49}$ Robert M. SAPOLSKY, Compórtate, op. cit., p. 725.

${ }^{50}$ Dan Ariely, Por qué mentimos, op. cit., p. 55.

${ }^{51}$ Dan Ariely, Por qué mentimos, op. cit., p. 190.

52 Dan Ariely, Por qué mentimos, op. cit., p. 221.

${ }^{53}$ En este sentido (Dan Ariely, Por qué mentimos, op. cit., p. 50), es muy interesante el efecto que, por ejemplo, tiene el hecho de obligar a las personas a firmar declaración fiscal (experimental) antes que después. En el primer caso, si la firma funciona como recordatorio moral, la tendencia es a engañar menos. En definitiva, "si las personas ponen su nombre en algún tipo de compromiso se ven empujadas a ser más honestas (al menos de forma temporal)".
} 
ROBERT M. SAPOLSKY, Compórtate, Barcelona, Capitan Swing, 2018.

CASS R. SUNSTEIN, La conformidad, Ciudad de México, Instituto Nacional Electoral, 2020.

CASS R. SUNSTEIN, Rumurología, Barcelona, Debate, 2a Ed, 2010.

STUART SUTHERLAND, Irracionalidad: el enemigo interior, Madrid, Alianza Editorial, 2a Ed, 2015.

RICHARD H. THALER, y CASS R. SUNSTEIN, Un pequeño empujón, Barcelona, Taurus, 2009.

ROBERT TRIVERS, La insensatez de los necios, Buenos Aires, Katz, 2013. 